\title{
Knocking at The Door: An Exploratory Field Study of Cadre Membership from the Leader's Perspective
}

\author{
Ernie Stark \\ Rochester Institute of Technology \\ Paul Poppler \\ Bellevue University
}

This study addresses an often-overlooked question in LMX research: What signals to a dyadic leader that one subordinate should be extended an exchange opportunity that may ultimately result in a unique strategic alliance while others are not extended such an offer? Conducted in a field setting, this exploratory study involved executives and upper level management of 17 firms in a Midwestern metropolis. Data secured from a sample of 155 matched dyadic pairs suggests that subordinate attractiveness appears predictable beyond random chance by the leader's subjective assessment of the subordinate's cognitive ability, veracity, and, to a much lesser degree, the subordinate's extra-role behavior.

\section{INTRODUCTION}

Prior to 1975, prevailing theories viewed leadership as homogenous across subordinates within workgroups and between workgroups (Phillips \& Bedeian, 1994; Cogliser \& Schriesheim, 2000). Dansereau, Graen, and Haga's work in 1975, originally termed Vertical-Dyadic Leadership (VDL), evolved into Leader-Member Exchange theory (LMX) that advanced a unique premise. Because leaders are confronted with limited time and resources within workgroups (Linden, Sparrowe, \& Wayne, 1997; Martin, Epitropaki, \& Thomas, 2010; Lee \& Chae, 2017), they develop distinctive dyadic relationships with individual subordinates for possible mutual advancements in areas of shared values, perspectives, and interests (Dienesch \& Linden, 1986; Graen \& Scandura,1987; Yu, Matta, \& Cornfield, 2018).

Dienesch and Linden (1986) observed that with the majority of subordinates the dyadic relationship is characterized by a leader's reliance on formal authority, rules, and policies that ensure subordinate

compliance toward supporting existing organizational processes and acceptable corporate citizenship behavior. In return for compliance, the leader guarantees continued subordinate access to customary organizational wages, salary, and benefits (Van Dyne, Cummings, \& McLean Parks, 1995; Stark \& Jeffries, 2011).

However, with a more limited number of subordinates, leaders appear to develop a distinctively different relationship. Graen and Schiemann (2013) referred to these relationships as Unique Strategic Alliances (USAs) wherein leaders become interdependent with subordinates as an option to secure additional resources without purchasing them. That is, the leader makes available scarce organizational 
resources under his or her control (e.g., challenging work assignments, promotions, mentoring per Graen \& Scandura, 1987; participation and input into decision-making per Scandura \& Graen, 1986) in exchange for prized resources controlled exclusively by focal subordinates that go beyond the traditional job paradigm and expectations such as engagement, job involvement, ownership, and reciprocal sacrificing (Graen \& Scandura, 1987; Tjosvold,1989; Yukl, 1998; Ordun \& Acar, 2014).

At the core of LMX theory is a concern with the degree of resource exchange necessary to differentiate relationships between workgroup leaders and individual subordinates (Kang \& Stewart, 2007; Wilson, Sin, \& Conlon, 2010; Martin, Guillaume, Thomas, Lee, \& Epitropaki, 2016). The continua of dyadic relationships in LMX theory encompasses a range of exchanges from a mutual understanding of the employment contract (mainly explicit) to exchanges where, according to Graen and Schiemann (2013), the leader's aim is to secure unique and interpersonal alliances that generate "priceless" scarce resources reflecting mutual trust, respect, commitment, and loyalty (mainly implicit). This range of exchange, combined with the fact that individual subordinates can decline dyadic offerings, has motivated volumes of commentary and inspired more than one thousand empirical studies of LMX theory (Sheer, 2015), and LMX has proven to be one of the most durable of all leadership theories (Walumbwa, Cropanzano, \& Goldman, 2011; Bauer \& Erdogan, 2016).

A preponderance of contemporary LMX research conducted in Western cultures points toward establishing high quality LMX relationships across as many employees as possible in order to increase the probability of achieving desirable work-related outcomes (Graen \& Schiemann, 2013; Nie \& Lämsä, 2015). Our study departs somewhat from this perspective in that we return to a focus seldom addressed since early research on the VDL model of leadership, the "cadre." Dansereau, Graen, and Haga (1975), Castleberry and Tanner (1986), and Graen and Uhl-Bien (1995) all made reference in their research to leaders creating a cadre of trusted assistants to help in the functioning of the work unit. Conceptually, a cadre can be understood as a basic organizational unit or structure composed of a small group of specialist or experts (Collins English Dictionary, 12 ${ }^{\text {th }}$ edition, 2014). We reasoned that regardless of the degree to which high quality LMX relationships might be dispersed across a workgroup, given the limitations on a leader's time and access to organizational resources (Graen \& Uhl-Bien, 1995; Liden, Sparrowe, \& Wayne,1997; Lee \& Chae, 2017), inevitably there will be a group of "go-to-high-quality-exchangesubordinates" (i.e., cadre members) on whom the dyadic-leader becomes increasingly dependent because of the relevance of their unique characteristics or expertise to the leader's high priority objectives.

\section{STATEMENT OF THE PROBLEM}

The LMX literature abounds with information about dyadic relationships that evolve as a result of resource exchanges (Yu, Matta, \& Cornfield, 2018) with most research examining dyadic exchanges that are social or affective in nature (Law, Wang, \& Chun, 2009; Martin, et al, 2016). These exchanges involve currencies such as respect, affect, support, loyalty, and obligation (Liden \& Maslyn, 1998; UhlBien \& Maslyn, 2003) and are frequently correlated with outcomes such as subordinate satisfaction, performance, commitment, and citizenship (Wilson, Sin, \& Conlon, 2010; Walumbwa, et al., 2011). While LMX research has focused on how the quality of the leader-subordinate relationship differentiates group membership in a manner that predicts the presence or absence of desirable organizational outcomes (Wang, Law, Hackett, Wang, \& Chen, 2005; Yu, et al. 2018), such research conspicuously forfeits a deeper understanding of constructs that spark the exchange relationship (Schriesheim, Castro, \& Cogliser, 1999; Den Hartog \& Koopman, 2002; Sheer, 2015).

This is an exploratory study, conducted in a field setting, and motivated by Sheer's (2015) criticism that LMX research forfeits an understanding of the exchange perspective. In general, the literature provides few insights regarding what makes some subordinates attractive for an exchange relationship and what makes others less attractive. More to the point, the literature fails to identify those attributes that signal to a dyadic leader that one subordinate should be extended an exchange opportunity that may ultimately result in cadre status and an ongoing USA while another subordinate is unlikely to experience such an opportunity. As an exploratory study, we make no assumption that non-cadre subordinates cannot 
or do not experience high quality LMX relationships, but we assume that not every subordinate experiencing high quality LMX could be considered a cadre member moving toward a USA with the dyadic leader. This study is unique because it attempts to move beyond the perspective of social and affective exchange currencies prevalent in the literature. The study's uniqueness is further enhanced in that it attempts to identify in a field setting specifically what dyadic leaders may perceive as scarce and desirable subordinate-held resources capable of enhancing the leader's effectiveness in accomplishing unstructured goals and objectives of a high priority (Schyns, Paul, Mohr, \& Blank, 2005; Harris \& Kacmar, 2006; Stark \& Jeffries, 2011).

\section{A RESOURCE EXCHANGE PERSPECTIVE OF CADRE MEMBERSHIP}

Graen and Scandura (1987) delineated a three-phase process conceptualizing the evolution of highquality resource exchange that has become a fundamental assumption of LMX research (Yu, Matta, \& Cornfield, 2018), and for the sake of brevity we are assuming that the reader is well-versed with this literature.

The idiosyncrasies and contextual peculiarities that moderate or mediate the exchange relationship have been the focus of many LMX studies. For example, studies that have been at the forefront of LMX include examination of the role of personalities (Nahrgang, Morgeson, \& Ilies, 2009; Sears \& Hackett, 2011), perceived similarity and liking (Liden, Wayne, \& Stilwell, 1993; Bauer \& Green, 1996: Dulebohn, $\mathrm{Wu}$, \& Liao, 2017), job clarity, meaningfulness, and predictability (Gregersen, Vincent-Höper, \& Nienhaus, 2016), trust (Major, Kozolowski, Chao, \& Gardner, 1995; Martin, et al., 2016; Byun, Dai, Lee, \& Kang, 2017), mutual respect (Graen \& Uhl-Bien, 1995; Scandura \& Lankau, 1996), and commitment to the leader (Settoon, Bennett \& Linden, 1996).

With the exception of Wakabayashi and Graen (1984), Scandura, Graen, and Novak (1986) and Novak and Graen (1987), few studies have departed far enough from contextual peculiarities and leader idiosyncrasies to consider specific subordinate job-related resources (either actualized or potential) that may contribute to ultimately achieving cadre status and developing a USA. Work by Emerson (1976) and Emerson, Cook, Gillmore, and Yamagishi (1983) provides a framework for understanding resource exchange from a dyadic leader's perspective. First, the resources possessed by a potential cadre member must have valance sufficient enough to be deemed critical to the leader's high priority goals and objectives. Given that task performance concerns the technical core of one's job (Van Iddekinge \& Ployhart, 2008), a subordinate whose resources are applicable only to task performance on a day-to-day basis would not likely merit the necessary investment to move that subordinate toward cadre status. Instead, a subordinate's resources would most likely need to be perceived as a set of behaviors with the potential to surpass the formal and mundane job requirements and contribute to producing goods or services that advance the leader's priority agenda (Graen \& Scandura, 1987; Schyns et al., 2005; Harris \& Kacmar, 2006; Graen \& Schiemann, 2013).

Second, the resource obtained by the leader must equal or exceed in value the resource offered for exchange. A dyadic leader is not going to invest scarce resources to receive behaviors from a subordinate that only marginally offset the leader's cost. Such resources must represent a means by which the leader achieves a valued goal or protects other valued assets. That is, the dyadic leader needs to perceive the subordinate's resources as having high potential to enhance the social or psychological context that supports job-related workgroup performance tasks ( $\mathrm{Ng} \&$ Feldman, 2009), promotes an atmosphere of cooperation and interpersonal support (Organ, Padsakoff, \& MacKenzie, 2006), or advances collective goal orientation (Reed, Srinivasan, \& Doty, 2009). In short, the dyadic leader is likely interested in identifying subordinates with resources necessary to contribute to meeting the most challenging and critical task facing the leader (Stark \& Poppler, 2009).

Finally, only a small minority of subordinates should be expected to possess resources that prove attractive to the leader (Emerson, et al. 1983; Wilson, Sin, \& Conlon, 2010), and the greater the scarcity of a resource deemed critical by a dyadic leader, the greater the motivation for a resource exchange. For example, declarative knowledge is not necessarily scarce and is easily transferable across employees 
(Ployhart, Van Iddekinge, \& Mackenzie Jr., 2011), and as such it may not be attractive to a leader for exchange. On the other hand, procedural knowledge in the form of "expertise" is mechanistic, intuitive, experiential, and can be inferred only by behavior of the actor (McCall, Arnold, \& Sutton 2008). Thus, procedural knowledge would be quite scarce and expected as valued for exchange by a dyadic leader.

As opposed to strictly social or affective currencies of exchange, this study proceeded on a premise suggested by Linden and Maslyn (1998) and Maslyn and Uhl-Bien (2001): the basis of cadre membership should be expected to be job-related commodities that a dyadic leader values but finds in scarce supply across the workgroup. We embraced this premise because a high quality exchange is not expected in the absence of work- or job-related currencies (Law, et al., 2009), the resources most expected to attract a leader's attention can generally be assumed to have some distinctiveness or become distinctive in combination with other resources critical for achievement of high priority goals (Scandura \& Graen, 1986), and such resources possess the potential to differentiate the ultimate contributions of an individual from the remainder of the workgroup (Nahrgang, Morgeson, \& Ilies, 2009).

\section{Research Question}

Accounting for a dyadic leader's idiosyncrasies, what perceptions held by a dyadic leader regarding job-related resources possessed by subordinates predict beyond random chance a subordinate's attainment of cadre membership across leader-member dyads?

\section{POPULATION AND SAMPLE}

Data for this study were secured from a population of 17 recognized "Employers of Choice" in the geographical area served by a university in a Midwestern metropolitan area of the U.S. These firms were identified as "Employers of Choice" per Herman and Gioia (2000) because of their recognized ability to hold top talent for long periods of employment. These employers responded to an initial invitation to participate in a study of managerial behavior in the metropolitan area. The industries and sectors represented by the participants included data processing, transportation, manufacturing, and governmental services.

Parallel surveys were constructed and mailed to 227 randomly selected dyads in which the dyadic subordinate was in a managerial or supervisory position. The achieved sample consisted of 155 matched pairs (e.g., subordinates who responded to the survey paired with their immediate supervisor who also responded).

Sixty-nine of the dyadic subordinates identified as male, and 84 identified as female (missing=2). Fifty-one of the subordinates were between 20 and 29 years of age, 48 were between 30 and 39 years, 35 were between 40 and 49 years, 18 were between 50 and 59 years, 2 were 60 years or over, and missing=1. Seventy-six of the dyadic subordinates identified as white and of European ancestry, and 78 identified as non-white and of non-European ancestry (missing=1). Ninety-seven of the subordinates held an undergraduate degree, and 57 held no such degree, (missing=1).

Eighty-nine of the dyadic leaders identified as male, and 65 identified as female (missing=1). Eleven of the supervisors were between the age of 20 and 29 years, 57 were between 30 and 39 years, 56 were between 40 and 49 years, 26 were between 50 and 59 years, and 4 were over 60 years. Eighty-nine of dyadic leaders identified as white and of European ancestry, and 66 identified as non-white and of nonEuropean ancestry (missing=2). One hundred and nine of the supervisors held undergraduate degrees, and 45 held no undergraduate degree (missing $=1$ ).

\section{MEASURES AND METHODS}

\section{Measures}

This study conceptualized work- or job-related "resources" as a supply or source of aid or support (i.e., knowledge, skill, ability, or trait possessed exclusively by individual subordinates) that can be resorted to when needed by a dyadic leader in order to enhance organizational effectiveness (suggested by 
the Collins English Dictionary, $12^{\text {th }}$ edition, 2014). Sensing that existing measures common to LMX research, primarily social and affective in nature, did not adequately address our specific interest, we designed our study to gain insight regarding how the dyadic resource concept operated in the field.

In the initial phase, an iterative qualitative route discussed by Srivastava and Hopwood (2009) was employed requiring an inductive process in which patterns, themes, and categories emerge from the data driven by reflection on what the inquirer wanted to know and interpretation according to subscribed frameworks and perspectives. University researchers began by conducting and recording interviews with 10 senior level executives of local businesses noted for employment of the university's graduates. The interviews inquired about the various configurations of knowledge, skills, abilities, and traits that would be considered significant work-relevant resources making an applicant attractive for hire at the managerial level. The interviews were then transcribed to electronic text and subjected to thematic analysis. Twenty-eight seemingly discrete themes (e.g., work-relevant resources) emerged from this process.

The research team then assigned distinctive definitions to these 28 work-relevant resources and constructed a questionnaire soliciting information regarding the relative priority of each resource in the context of achieving the most important strategic business initiatives in the upcoming five years. This questionnaire was sent to over 100 senior and mid-level executives in the metropolitan area with the ultimate goal being to coalesce around ten highly prioritized employee possessed resources. Fifty-one executives responded to the survey. In the final analysis, we determined that there was a coalescence around approximately ten resources considered highly relevant to the work environment in the metropolitan area, almost exclusively under control of a manager in a position subordinate to a dyadic leader, and a job-related currency with valance strong enough for the dyadic-leader to proffer an exchange relationship.

We then set about seeking published measures that adequately reflected the constructs inherent in the ten job-relevant resources emerging from the field study, and where no comparable measure could be found, we constructed appropriate scales. Parallel surveys were constructed and mailed to 227 randomly selected dyads (subordinates and immediate supervisor) in the 17 organizations participating in the study and data were secured from 155 dyadic leaders whose subordinate had also responded.

\section{Predictive Measures}

Capacity for trustworthiness. This resource was defined as maintaining social, ethical, and organizational norms regarding job-related activities. Often observed as one being trustworthy, authentic, and just in relationships in the workplace (Church,1995). A 9-item scale suggested by Church (1995) measuring personal integrity was employed in this study. For instance, one item asked about the dyadic leader's agreement ( $1=$ strongly disagree to $6=$ strongly agree) with the statement, "This subordinate fails to follow through on commitments." This particular item was reversed scored so that high scores on the scale reflected greater levels of perceived personal integrity, thus enhancing the likelihood that the subordinate would be evaluated as trustworthy and authentic. The scale produced a Cronbach's alpha of .91 in this study, as indicative of the dyadic leader's perception that the subordinate possessed higher capacity for trustworthiness than lower scoring subordinates

Capacity for analytical reasoning. Boyatzis, Cowen and Kolb (1994) defined a subordinate's capacity for analytical reasoning as reaching decisions through a logical and rational process rather than relying exclusively on experience or intuition. An 8-item scale was constructed following the suggestions of Boyatzis et al. (1994). For instance, one item asked the dyadic leader to determine how accurate the following statement was of the subordinate $(1=$ totally inaccurate to $6=$ extremely accurate): "Reduces large amounts of information by using a scheme not previously applied to the information." Higher scores on the scale were interpreted as indicative of the dyadic leader's perception that the subordinate possessed higher levels of analytical reasoning ability than lower scoring subordinates. The scale produced a Cronbach's alpha of .86 in this study.

Capacity for planning. This resource was defined as identifying and organizing future or intended actions with a desired result or direction, and it is often observed in setting goals, outlining a series of 
actions, and organizing materials and activities to accomplish specific objectives (Boyatzis et al., 1994). A 7-item scale was developed following the suggestions of Boyatzis et al. (1994). For example, one item asked the dyadic leader to evaluate how effective (1=totally ineffective to $6=$ exceedingly effective) the subordinate was in regard to evaluating and computing risks in a situation before taking action. Higher scores on this scale were interpreted as indicative of the dyadic leader's judgment that a subordinate possessed greater capacity for planning job-related activities than subordinates with lower scores. The scale produced a Cronbach's alpha in this study of .93.

Capacity for systems thinking. This resource was defined by an ability to order multiple causal events. This resource often appears as a disposition for seeing "the Big Picture," anticipating consequences, and avoiding undesirable "downstream events (Boyatzis et al.,1994). Two items were constructed following the suggestions of Boyatzis et al. (1994). One item asked the dyadic leader how accurately ( $1=$ totally inaccurate to $6=$ extremely accurate) the subordinate was in describing multiple cause-and-effect relationships in terms of a schematic, plan of action, or flow diagram. Higher scores on these two items were interpreted as indicative of the dyadic leader's perception that a subordinate possessed greater capacity for systems thinking than subordinates with lower scores. The correlation between scores on the two items was .66.

Capacity for communication. This resource was defined as adeptness in ensuring that important information is communicated throughout a firm, and it often appears as a request from information from superiors or sharing relevant information with peers and direct reports. University researchers developed a six-item scale to report on this perceived resource. For instance, one item asked the leader's agreements ( $1=$ strongly disagree to $6=$ strongly agree) with the statement, "When changes are made, the subordinate does a good job of explaining the nature of the changes." Higher scores were interpreted as indicative of the dyadic leader's judgment that the subordinate possessed greater capacity for communication in the workplace than those with lower scores. The scale produced a Cronbach's alpha in this study of .82 .

Capacity for initiative. This resource was defined as willingness to take action to achieve something, which often appears as taking an action prior to being asked, forced, or provoked (Boyatzis, et al., 1994). Following the suggestions of Boyatzis, et al. (1994), a four-item scale was constructed inquiring about the leader's perception of a subordinate's capacity for taking initiative. For instance, one item asked the leader's agreement $(1=$ strongly disagree to $6=$ strongly agree) with the statement that the subordinate determines a course of action by using sources of information not typically used by others. The scale produced a Cronbach's alpha in this study of .76, and a higher score was interpreted as indicative of the dyadic leader's perception of the subordinate's greater capacity for initiative when compared with lower scoring subordinates.

Capacity for teamwork. Faced with rapidly changing and competitive environments, companies are frequently turning to team-based approaches to build and maintain high performance (Gardner, Gino, \& Staats, 2012), and success in doing so may well determine the future for many firms (Warrick, 2016). Five items from a scale by Church (1995) were used to determine how a dyadic leader evaluated a subordinate's capacity for teamwork. For example, one item asked how effective ( $1=$ totally ineffective to $6=$ exceedingly effective) the subordinate was in recruiting the assistance and support of all individuals critical to a project's success. Higher scores on this scale were interpreted as the leader's perception that the subordinate possessed greater capacity to contribute to the success of team projects than those with lower score. The scale produced a Cronbach's alpha of .89 in this study.

Capacity for customer service. This resource was defined by the researchers as an interest that customers remain with the firm, and it often appears as behaviors focusing on quality standards. University researchers constructed a five-item scale inquiring about the leader's perception of a subordinate's capacity to take actions directed toward ensuring customer satisfaction. For instance, one item inquired about the leader's agreement ( $1=$ strongly disagree to $6=$ strongly agree) with the statement that the subordinate keeps others aware of how their behavior impacts customer satisfaction. A higher score was interpreted as the dyadic leader's perception of the subordinate's greater capacity for customer service when compared with lower scoring subordinates. The scale produced a Cronbach's alpha 86. 
Capacity for extra-role citizenship. This resource was defined as going beyond the narrow confines of the job or in-role behavior, and it often appears as unselfish concerns for the welfare of others, acts of consideration and politeness, concerns for doing what is right and just, and concerns for the affairs and well-being of the firm (Niehoff \& Moorman, 1993). Turning to work by Van Dyne, Graham, and Dienesch (1994), a 14-item scale was constructed measuring various extra-role citizenship behaviors such as loyalty, obedience, social participation, advocacy participation, and functional participation. For example, one item inquired about the accuracy ( $1=$ totally inaccurate to $6=$ extremely accurate) of the statement: "This subordinate would not attend work related meetings unless required by the job". The scale produced a Cronbach's alpha in this study of .87, and a higher score was interpreted as the dyadic leader's perception of the subordinate's greater capacity for extra role behavior than lower scoring subordinates.

Capacity for in-role citizenship. This resource was defined as subordinate behavior prescribed by a job description and reinforced by the formal reward system (Barksdale \& Warner, 2001). A three-item scale was taken from work by Williams and Anderson (1991) to measure the dyadic-leader's perception of the subordinate's in-role behavior. For instance, one item inquired about the leader's agreement ( $1=$ strongly disagree to $6=$ strongly agree) with the statement that the subordinate meets performance expectations associated with the position. The scale produced a Cronbach's alpha in this study of .77, and higher scores were interpreted as the dyadic leader's perception of the subordinate's greater capacity for in-role citizenship behavior than lower scoring subordinates.

\section{Response Variables}

High-quality LMX. Four items from a seven-item scale described by Wayne, Shore, and Liden (1997) were used in the study to measure the quality of the LMX. This particular scale is most frequently administered to subordinates in a dyadic relationship. However, given that this study sought to examine LMX from the perspective of the dyadic leader, the items were revised and administered to the immediate supervisor in this study. Thus, as administered, the scale reflects to some degree the resources the leader appears willing to exchange with the subordinate. For example, the dyadic leader was asked to indicate the level of agreement $(1=$ strongly disagree to $6=$ strongly agree $)$ with the statement, "Regardless of how much power is built into my position, I would be personally inclined to use that power to help this subordinate solve problems in his/her work." A high score was interpreted as indicative of a high-quality relationship characterized by frequent reciprocal exchanges between the leader and the subordinate. This four-item scale produced a Cronbach's alpha of .84 .

Cadre status. Since cadre status is seldom discussed beyond early VDL research, no particular demarcation currently exists. Our assumption was that both cadre and non-cadre subordinates can and do experience high quality LMX, but only a small minority of subordinates are likely to control job-related currencies of sufficient valence to the dyadic-leader to be recognized as cadre members. That is, because of the scarcity of the job-relevant resource controlled by a cadre subordinate, the greater dyadic-leader's motivation for exchange. We followed the example of Stark and Jeffries (2011) and employed a rather rigorous standard to increase the likelihood that cadre subordinates were being properly identified in this study. Only scores at or above the 75th percentile on the measure of LMX were coded as 1 and defined as indicative of cadre status in the exchange relationship $(n=42)$, and all other scores were coded 0 and classified as non-cadre subordinates $(\mathrm{n}=113)$.

\section{Control Variables}

Leader Idiosyncrasies. "Liking" as a reflection of interpersonal attraction has emerged as a primary construct in LMX research (Dulebohn, Wu, \& Liao, 2017) and, over the past 60 years, the similarityattraction paradigm has been employed to understand interpersonal attraction in dyadic relationships (Mannix \& Neal, 2005; Tidwell, Eastwick, \& Finkel, 2013; Kaptein, Castaneda, Fernandez, \& Nass, 2014). The old saw "birds of a feather flock together" may certainly hold true in the development of leader-member dyads (Liden, et al.,1997; Kim, Han, Son, \& Yun, 2017), and a meta-analysis by Dulebohn, Bommer, Liden, Brouer, \& Farris (2012) suggested that demographic similarity in the dyadic 
relationship correlates positively with measures of LMX. Thus, it was deemed necessary to construct measures of the degree to which the demographic characteristics of the dyadic leader were reflected in the characteristics of the subordinate about whom the leader was reporting. Following the logic of Cohen, Cohen, West and Akin (2003), a categorical variable was constructed in which 0 indicated that the leader's gender was different from that of the subordinate $(n=53)$ and a 1 indicated the leader and subordinate were of the same gender $(\mathrm{n}=99)$. This process of dummy coding enabled statistical analysis using techniques that assume interval level data on variables measured only at the nominal level. The same procedure was followed regarding race with 0 indicating that the dyadic leader was of a race different from that reported by the subordinate $(\mathrm{n}=77)$ and 1 indicating leader and subordinate were of the same racial identity $(n=75)$. Regarding age, a 1 indicated the leader's age fell within the same decade grouping as the subordinate (e.g., 20-29, 30-39, etc.) for which $\mathrm{n}=42$, and 0 indicated that the leader age was outside of that decade grouping $(\mathrm{n}=108)$.

\section{Methods}

\section{Accounting for Response Bias}

McIntire and Miller (2007) defined response bias as response patterns that result in false or misleading information, and that can systematically lead to selecting one response over another (Nunnally $\&$ Bernstein,1994). Three approaches to address such bias were utilized in the construction of the survey instrument. First, some items were reversed worded in an attempt to balance positive and negative statements. Second, scales were given differing response format (e.g. agree/disagree, accurate/inaccurate, effective/ineffective, etc.). Third, items within each scale often appeared at different points in the survey instrument, but the response format for individual items on the same format did not vary.

\section{Violation of Assumptions}

All continuous variables were examined for evidence of departure from the assumptions of linear normality. None demonstrated skewness or kurtosis values in excess of 1.0 thus justifying the conclusion there was no evidence of non-linearity in the variables.

\section{Principle Component Analysis}

Given the large number of items (63) across the scales and the likelihood of construct overlap, it was deemed desirable to employ a principle component analysis (PCA) with orthogonal rotation to transform the data into fewer and more distinct dimensions. PCA reduces data geometrically projecting them into linearly uncorrelated values (principle components) with the goal of finding the best summary of the data using a limited number of components (Lever, Krzywinski, \& Altman, 2017).

Ten factors emerged with eigenvalues greater than 1 explaining in excess of $68 \%$ of the common variance. Items that loaded less than .50 on a factor or cross-loaded in excess of .40 were removed. The first five factors accounted for $56 \%$ of the common variance and were retained for further analysis in light of the fact that the remaining five factors demonstrated a leveling-off of eigenvalues on the scree plot and contained an insufficient number of primary loadings.

The first factor was comprised of 10 items $(\alpha=.94)$ seven referring to a subordinate's capacity for both trustworthiness, authenticity, and initiative and accounted for $43 \%$ of the common variance. This factor was labeled "Veracity." The second factor was comprised of 10 items $(\alpha=.93)$, seven of which referred to a subordinate's capacity to plan and organize; these accounted for $5 \%$ of the common variance. This factor was labeled "Structuring Skills." The third factor was comprised of six items $(\alpha=.89)$, five of which referred to a subordinate's capacity for logical and rational decision-making, and accounted for $4 \%$ of the common variance. This factor was labeled "Analytical Reasoning." The fourth factor was comprised of six items $(\alpha=.87)$ all referring to a subordinate's capacity to abide by rules and to display appropriate behavior; these accounted for 3\% of common variance. This factor was labeled "In-role Citizenship." The fifth factor was comprised of five items $(\alpha=79)$ all of which referred to a capacity for behavior that benefited the employer or workgroup; these accounted for $1 \%$ of the common variance. This factor was labeled "Extra-role Citizenship." 


\section{Missing Values}

Missing values are a consistent problem in survey research. Tabachnick and Fidell (2013) noted that in the absence of all other information, when dealing with continuous variables the mean is best guess about the value of a variable because it is conservative, given that the mean for the distribution does not change. Where missing values did occur within a continuous variable, the mean for the particular scale was substituted.

\section{Data Analysis}

The challenge in this study was to determine what, if any, combination of the identified five factors predicted, beyond random chance, cadre status membership. Given that both continuous and categorical variables could be considered as predictors of cadre membership, the defensible method of data analysis initially appeared to be logistic regression. However, logistic regression generally requires a minimum of 50 cases per predictor (Grimm \& Yarnold, 1995; Tabachnick \& Fidell, 2013; Harlow, 2014), and the observations in this study fell well short of that requirement. This fact pointed us toward discriminant analysis given that the primary goal of discriminant analysis is to find the dimension(s) along which groups differ and to find classification functions to predict group membership (Tabachnick \& Fidell, 2013).

While solid theoretical justification existed for developing the categorical predictors toward determining the influence of the similarity-attraction paradigm on cadre membership, examination of the correlation between the variables in this study demonstrated no significant correlation with either the response variable or the predictor variables of interest. Thus, a decision was made to drop the categorical variables and conduct a general discriminate analysis using the unique continuous variables as predictors. Further, given that the rigorous classification scheme for determining cadre membership resulted in unequal groups, prior probabilities were estimated from the size of the individual groups.

\section{RESULTS}

The goal of discriminant analysis is to determine if group membership can be predicted beyond random chance by a "best" combination of predictor variables and then determine which of the predictor variables differentiate most clearly between group membership (Harlow, 2014). 
TABLE 1

DESCRIPTIVES AND CORRELATIONS RAW SCORES

\begin{tabular}{|c|c|c|c|c|c|c|c|c|c|c|c|c|}
\hline & Variable & $\mathrm{N}$ & Mean & $\mathrm{SD}$ & 1 & 2 & 3 & 4 & 5 & 6 & 7 & 8 \\
\hline 1 & Age Match & 154 & .299 & .45 & & & & & & & & \\
\hline 2 & Racial Match & 152 & .493 & .501 & -.049 & & & & & & & \\
\hline 3 & $\begin{array}{l}\text { Gender } \\
\text { Match }\end{array}$ & 152 & .651 & .478 & .051 & .153 & & & & & & \\
\hline 4 & Veracity & 155 & 4.711 & .772 & .038 & .008 & -.050 & & & & & \\
\hline 5 & $\begin{array}{l}\text { Structuring } \\
\text { Skills }\end{array}$ & 155 & 4.427 & .817 & .004 & .013 & -.032 & $.727 * *$ & & & & \\
\hline 6 & $\begin{array}{l}\text { Analytical } \\
\text { Reasoning }\end{array}$ & 155 & 4.201 & .837 & .002 & .040 & -.034 & $.737 * *$ & $.800 * *$ & & & \\
\hline 7 & $\begin{array}{c}\text { In-Role } \\
\text { Citizenship }\end{array}$ & 155 & 4.748 & .888 & .014 & .024 & -.027 & $.760 * *$ & $.688 * *$ & $.662 * *$ & & \\
\hline 8 & $\begin{array}{l}\text { Extra-Role } \\
\text { Citizenship }\end{array}$ & 155 & 4.592 & .967 & .078 & -.021 & .022 & $.556^{* *}$ & $.546^{* *}$ & $.498 * *$ & $.536^{* *}$ & \\
\hline 9 & LMX & 155 & 4.95 & .779 & .029 & -.050 & -.080 & $.799 * *$ & $.662 * *$ & $.693 * *$ & $.685^{* *}$ & $.556^{* *}$ \\
\hline
\end{tabular}

$* * \mathrm{p}<.001$

Toward the first goal, a Wilk's Lamba of .595 (Chi-square $=69.870, \mathrm{df}=5, \mathrm{p}<.001$ ) gave evidence of a significant association between group membership and a linear combination of predictor variables. A single discriminate function emerged from the analysis with an associated eigenvalue of .681 and a canonical correlation of .637. Squaring the canonical correlation per Tabachnick and Fidell (2013) revealed that the emerging discriminate function explained about $40.5 \%$ of the variance between the cadre and non-cadre groups.

The standardized canonical function presented in Table 2 represents the correlation between the predictor variables and the emerging discriminate function. A large coefficient indicates that cadre and non-cadre groups possibly differ greatly on a particular variable. The largest correlation was the measure of the manager's perception of the subordinate's capacity for analytical reasoning followed by the perception of the subordinate's capacity for veracity. Squaring the standardized discriminate functions per Harlow (2014) revealed that the proportion of shared variance between the measure of analytical reasoning and the emerging discriminant function was about $26 \%$, the measure of veracity and the emerging discriminant function was $23 \%$, while the measure of subordinate capacity for extra-role citizenship was $3 \%$. Table 3 presents the structure matrix representing the order in which the predictor variables loaded on the discriminant function. Examination of Figure 1 clearly illustrates that a single function best discriminated between cadre and non-cadre membership in this study, and two predictor variables loaded most strongly on this function: the leader's perception of the subordinate's capacity for analytical reasoning and perception of the subordinate's capacity for veracity. Employing the best linear combination of predictor variables from the standardized canonical functions enabled accurately accounting for group membership of about $84 \%$ of the 155 subordinates in the sample contrasted with prior probabilities. 
TABLE 2

STANDARDIZED CANONICAL FUNCTIONS

\begin{tabular}{|l|c|}
\hline & $\begin{array}{c}\text { Function } \\
1\end{array}$ \\
\hline Veracity & .478 \\
\hline Structuring Skills & -.008 \\
\hline Analytical Reasoning & .512 \\
\hline In-role Citizenship & .036 \\
\hline Extra-role Citizenship & .185 \\
\hline
\end{tabular}

TABLE 3

STRUCTURE MATRIX

\begin{tabular}{|l|c|}
\hline & $\begin{array}{c}\text { Function } \\
1\end{array}$ \\
\hline Veracity & .887 \\
\hline Analytical Reasoning & .876 \\
\hline Structuring Skills & .769 \\
\hline In-role Citizenship & .696 \\
\hline Extra-role Citizenship & .589 \\
\hline
\end{tabular}




\section{FIGURE 1 \\ COMPARATIVE GROUPINGS ON THE DISCRIMINATE FUNCTION}

\section{Canonical Discriminant Function 1}

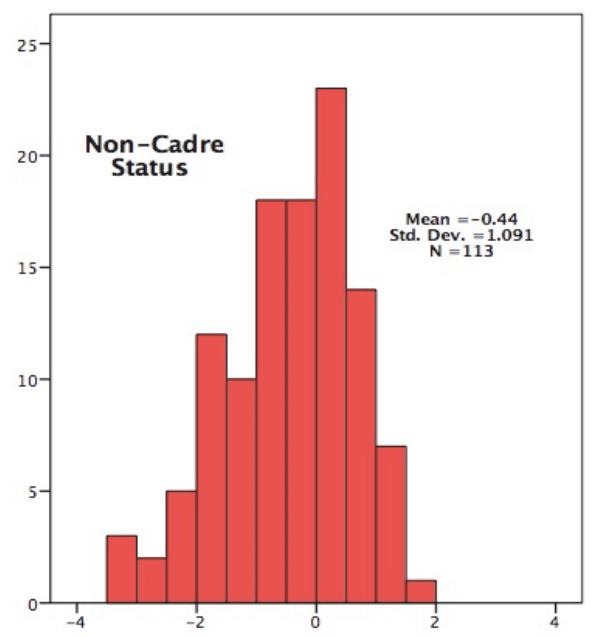

\section{Canonical Discriminant} Function 1

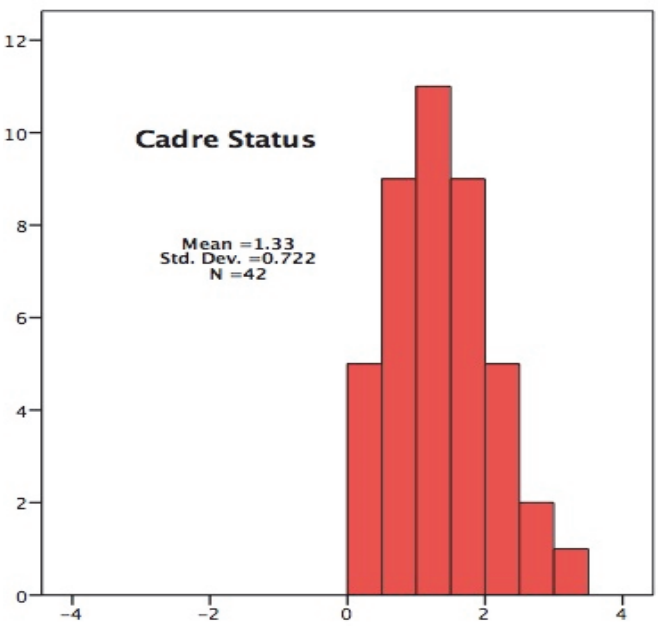

\section{DISCUSSION}

We reasoned that regardless of the degree to which high quality LMX relationships may be dispersed across a workgroup and given the limitations on a leader's time and access to organizational resources inevitably there will be a group of "go-to-high-quality-exchange-subordinates" (i.e., cadre members) on whom the dyadic-leader becomes increasingly dependent because of the relevance of their unique characteristics or expertise to the leader's high priority objectives. Our exploratory study is noteworthy in that results suggest that such cadre members may differ from non-cadre members on a single discriminant function influenced by the leader's assessment of the subordinate's capacity for analytical reasoning, veracity, and to a much smaller degree, extra-role behaviors. Prior LMX research has addressed numerous social and affective resource currencies that subordinates bring to an exchange relationship (e.g., admiration and respect of the leader, effort and performance, citizenship behaviors, gifts to the leader, lateral information, etc.), but few studies appear to have considered how resources of the nature investigated in this study might influence an exchange relationship. The strength of the loading of "Analytical Reasoning" (i.e., the leader's perception of the subordinate's capacity for logical and rational decision-making) was not anticipated in light of previous LMX literature. Our measure of analytical reasoning almost certainly represents some manifestation of the leader's assessment of a subordinate's cognitive ability. Work by Ree, Earls, and Teachout (1994) and Schmidt and Hunter (2004) lends support to a commonly-held perception that the best single predictor (but not the only predictor) of work-related performance is general cognitive ability. Given that individuals with greater levels of cognitive ability learn faster, have greater absorptive capacity, and generalize their knowledge across dissimilar situations more effectively (Gootfredson, 1997; Jensen, 1998; Judge, Klinger, \& Simon, 2010), the influence of such an assessment by a dyadic leader on an exchange relationship is understandable. Further, there is adequate theory and research of resource allocation to consider a subordinate's cognitive ability as a resource that leaders can deploy to achieve desired outcomes (Van Iddenkinge, Aguinis, \& Mackey, 2017). In short, perceptions of a subordinate's cognitive ability may well signal the attractiveness for an exchange relationship that could culminate in cadre status and a USA.

The measure "Veracity" emerging from the PCA reflects perceptions regarding a subordinate's capacity for trustworthy, authentic, and initiative-oriented behavior. Its strength in loading on the 
discriminant function was not unanticipated given that previous LMX research has pointed to the influence of currency of this nature on exchange relationships (e.g., Major, Kozolowski, Chao, \& Gardner, 1995; Martin, et al., 2016; Byun, et al., 2017). We would suggest that a case could be argued that this is manifestation of the personality trait commonly termed "conscientiousness" (i.e., being diligent, reliable, efficient, responsible, organized, dutiful, achievement-oriented, and goal-directed per McIlveen, Beccaria, \& Burton, 2013), and as a personality trait, it would not be evenly distributed across all subordinates. Work by Bernerth, Armenakis, Field, Giles, and Walker (2007) and Lapierre and Hackett (2007) imply that personality traits may be viewed as resources that can be secured through LMX and applied to further the leader's most important goals and objectives. Thus, there is reason to suggest that demonstration of veracity may be viewed by a dyadic leader as signaling a subordinate's attractiveness for further exchange and possible movement toward cadre status in a USA.

Examination of factor loadings on the structure matrix alludes to an amalgam of dyadic leader perceptions regarding subordinate resources that might prove attractive for exchange, each worthy of further research and discussion. However, the strength of the loading of veracity and analytical reasoning appears logical given work by Gonzalez-Mulé, Mount, and Oh (2014) inferring that general mental ability, foremost, and traits associated with the Five Factor Model would be seen as desirable resources by leaders confronted with disconcerting work related issues that defy attempts to alleviate.

\section{LIMITATIONS}

First, this study was exploratory in nature and did not seek to test an a priori causal model, but we would argue that a strength of our study is the fact it explored and expanded upon data collected in a field setting from organizations under realistic work conditions. Second, we are sensitive to the charge that our data were obtained from 17 firms in the Midwest, a population that is often considered both geographically and culturally unique. In response, we would recommend further study applying our capacity measures to other "employers of choice" in other regions and industries, each of which would be distinctive by organizational differences in high priority goals and by dyadic leader motivations for specific USAs. Third, we readily acknowledge that in exploring the concept of resource exchange in social settings we are dealing with intangibles, but we would counter with Cascio and Boudreau's (2008) admonition: intangible does not necessarily mean immeasurable. Finally, rather than generalizing the results of this study to a larger population, the results should be used to stimulate reflection and theory development regarding perceptions of dyadic leaders about scarce and valued resources that promote or reduce subordinate movement toward cadre membership, even in the presence of highly dispersed LMX relationships.

\section{CONCLUSION}

Work by Graen and Schiemann (2013) intimates that while cadre subordinates and non-cadre subordinates will do about the same amount of business-as-usual-work, cadre subordinates can be expected to do most of the important problem solving and engage in USAs. Thus, it appears reasonable that the variables appearing in the structure matrix represent a set of constructs surpassing the formal and mundane job requirements and contributing to production of goods or services that advance the leader's priority agenda. Further, there is reason to believe that these resources are perceived by a leader as more than marginally offsetting the cost in the exchange because they provide a means of achieving a valued goal or protecting other important resources. Ultimately, scarcity increases their value and a leader's motivation for exchange, and given that the two factors loading most strongly on the matrix are possible manifestations of cognitive ability and conscientious behavior (both of which could not be anticipated as evenly distributed across a work place population), relatively few subordinates will be perceived as possessing such resources. Regarding those who appear to be in possession of such resources, leaders are likely motivated toward a high-level of exchange in light of the potential to address perplexing problems that defy resolution by the leader alone, thus opening a path to cadre status.

Journal of Organizational Psychology Vol. 19(3) 2019115 


\section{REFERENCES}

Barksdale, K., \& Werner, J. M. (2001). Managerial ratings of in-role behaviors, organizational citizenship behaviors, and overall performance: testing different models of their relationship. Journal of Business Research, 51,145-155.

Bauer, T.N., \& Erdogan, B. (2016), Leader-member exchange (LMX) theory: an introduction and overview, in Bauer, T.N. and Erdogan, B.E. (Eds), The Oxford Handbook of Leader-Member Exchange, Oxford University Press, New York, NY, 3-9.

Bauer, T. N., \& Green, S. G. (1996). Development of leader-member exchange: A longitudinal test. Academy of Management Journal, 39(6), 1538-1567.

Bernerth, J. B., Armenakis, A. A., Field, H. S., Giles, W. F., \& Walker, H. J. (2007). Is personality associated with perceptions of LMX? An empirical study. Leadership \& Organizational Development Journal, 28(7), 613-631.

Boyatzis, R. E., Cowen, S. S., \& Kolb, D. A. (1994). Innovation in professional education: Steps on a journey from teaching to learning. San Francisco, CA: Jossey Bass.

Byun, G., Dai, Y., Lee, S., \& Kang, S. (2017). Leader trust, competence, LMX, and member performance: A moderated mediation framework. Psychological Reports, 120(6), 1137-1159.

Cascio, W. F., \& Boudreau, J. W. (2008). Investing in people. Saddle River, NJ: Person Education.

Castleberry, S. B., \& Tanner, J. F. (1986, November). The manager-salesperson relationship: An exploratory examination of the Vertical-Dyad Linkage model. Journal of Personal Selling and Sales Management, 29-37.

Chen, X, He, W., Weng, L. (2018). What is wrong with treating followers differently? The basis of leader-member exchange differentiation matters. Journal of Management, 44(3), 946-971.

Church, A. H. (1995). Managerial behaviors and work group climate as predictors of employee outputs. Human Resource Development Quarterly, 6(2), 173-205,

Cogliser, C. C., \& Schriesheim, C. A. (2000). Exploring work unit context and leader-member exchange: a multi-level perspective. Journal of Organizational Behavior, 21, 487-511.

Cohen, J. Cohen, P. West, S. G. and Aiken, L. S. (2003), Applied multiple regression/correlation analysis for the behavioral science. Mahwah, NJ: Lawrence Erlbaum Associates.

Collins English Dictionary $\left(2014,12^{\text {th }}\right.$ ed.) Retrieved from https://ezproxy.rit.edu/login?url=https://search.credoreference.com/content/entry/hcengdict/cadre/ 0 ?institutionId $=3255$.

Dansereau, F. Jr., Graen, G., \& Haga, W. J. (1975). A vertical dyad linkage approach to leadership within formal organizations: A longitudinal investigation of the role making process. Organizational behavior and human performance, 13, 46-78.

Den Hartog, D. N., \& Koopman, P. L. (2002). Leadership in organizations. In (Niel Anserson, Deniz S. Ones, Handan Kepir Sinangil, and Chockalingam Viswesvaran, eds), Handbook of Industrial, Work, \& Organizational Psychology, 2, Thousand Oaks, CA: Sage.

Dienesch, R. M., \& Liden, R. C. (1986). Leader-member exchange model of leadership: A Critique and future development. Academy of Management Review, 11, 618-634.

Dulebohn, J. H., Bommer, W. H., Liden, R. C., Brouer, R.L. \& Ferris, G. R. (2012). A meta-analysis of antecedents and consequences of leader-member exchange: Integrating the past with an eye toward the future. Journal of Management, 38(6), 1715-1759.

Dulebohn, J. H., Wu, D., \& Liao, C. (2017). Does liking explain variance above and beyond LMX? A meta-analysis. Human Resource Management Review, 27, 149-166.

Emerson, R. M. (1976). Social exchange theory, Annual Review of Sociology, 2, 335-362.

Emerson, R. M., Cook, K.S., Gillmore, M. R., \& Yamagishi, T. (1983). Valid predictions from invalid comparisons: Response to Heckathorn. Social Forces, 61, 1232-1247.

Gardner, H. K., Gino, F., \& Staats, B. R. (2012). Dynamically integrating knowledge in teams: Transforming resources into performance. Academy of Management Journal, 55(4), 998-1022. 
Gonzalez-Mulé, E., Mount, M. K., \& Oh, I. (2014). A meta-analysis of the relationship between general mental ability and non-task performance. Journal of Applied Psychology, 99(6), 1222-1243.

Gootfredson, L. S., (1997). Mainstream science on intelligence: An editorial with 52 signitures, history, and bibliography, Intelligence, 24, 13-23.

Graen, G. B., \& Scandura, T. A. (1987). Toward a psychology of dyadic organizing. Research in Organizational Behavior, 9, 175-208.

Graen, G. B., \& Schiemann (2013). Leadership-motivated excellence theory: an extension of LMX. Journal of Managerial Psychology, 28(5), 452-469.

Graen, G. B., \& Uhl-Bien, M. (1995). Relationship-based approach to leadership: Development of leadermember exchange (LMX) theory of leadership over 25 years. Leadership Quarterly, 6, 219-247.

Gregersen, S., Vincent-Höper, S., \& Nienhaus, A. (2016). Job-related resources, leader-member exchanges and well-being-a longitudinal study. Work and Stress, 30(4), 356-373.

Grimm, L. G., \& Yarnold, P. R. (1995). Reading and understanding multivariate statistics. Washington, D.C.: American Psychological Association.

Harlow, L. L. (2014). The essence of multivariate thinking: Basic themes and methods (2nd ed.). New York, NY: Routledge/Taylor \& Francis Group.

Harris, K. J., \& Kacmar, K. M. (2006). Too much of a good thing: The curvilinear effect of leadermember exchange on stress, Journal of Social Psychology, 146(1), 65-84.

Herman, R. E., \& Gioia, J. L. (2000). How to become an employer of choice. Naperville, IL: Oak Hill.

Jensen, A. R. (1998). The g factor: The science of mental ability. Westport, CT: Greenwood Publishing.

Judge, T., Klinger, R. L., \& Simon, L. S. (2010). Time is on my side: General mental ability, human capital, and extrinsic career success. Journal of Applied Psychology, 95(1), 92-107.

Kang, D., \& Stewart, J. (2007). Leader-member exchange (LMX) theory of leadership and HRD: Development of units of theory and laws of interaction. Leadership \& Organization Development Journal, 28(6), 531-551.

Kaptein, M., Castaneda, D., Fernandez, N., \& Nass, C. (2014). Extending the similarity-attraction effect: The effects of when-similarity in computer-mediated communication. Journal of ComputerMediated Communication, 19(3), 342-357.

Kim, S. C., Han, S., Son, S. Y., \& Yun, S. (2017). Exchange ideology in supervisor-subordinate dyads, LMX, and knowledge sharing: A social exchange perspective. Asian Pacific Journal of Management, 34, 147-172.

Law, K. S., Wang, H., \& Chun, H. (2009). Currencies of exchange and global LMX: How they affect employee task performance and extra-role behavior. Asia Pacific Journal of Management, 27, 625-646.

Lapierre, L. M., \& Hackett, R. D. (2007). Trait conscientiousness, leader-member exchange, job satisfaction and organizational citizenship behavior: A test of an integrative model. Journal of Occupational and Organizational Psychology, 80, 539-554.

Lee, K., \& Chae, Y. J. (2017). LMX differentiation, diversity, and group performance. Career Development International, 22(2), 106-123,

Lever, J., Krzywinski, M., \& Altman (2017). Points of significance: Principle component analysis. Nature Methods, 14(7), 641-642.

Liden, R. C., \& Maslyn, J. M. (1998). Multidimensionality of leader-member exchange, An empirical assessment through scale development. Journal of Management, 24, 43-72.

Liden, R. C., Sparrowe, R. T., \& Wayne, S. J. (1997). Leader-member exchange theory: The past and potential for the future, in $\mathrm{G}$. Ferris (Ed), Research in personnel and human resource management, 15, 47-120.

Liden, R. C., Wayne, S. J., \& Stilwell, D. (1993). A longitudinal study of the early development of leadermember exchanges. Journal of Applied Psychology, 78(4), 662-674.

Major, D. A., Kozlowski, S. W. J., Chao, G. T., \& Gardner, P. D. (1995). A longitudinal investigation of newcomer expectations, early socialization outcomes and the moderating effects of role development factors, Journal of Applied Psychology, 80, 418-431. 
Mannix, E., \& Neale, M. A. (2005). The promise and reality of diverse teams in organizations, Psychological Science, 6(2), 31-56.

Martin, R., Epitropaki, O., \& Thomas, G. (2010). A review of Leader-Member Exchange (LMX) research: Future prospects and directions. In G.P. Hodgkinson and J.K. Ford (Eds.) International Review of Industrial and Organizational Psychology, 25, 35-88.

Martin, R., Guillaume, Y., Thomas, G., Lee, A., \& Epitropaki, O. (2016). Leader-member exchange (LMX) and performance: A meta-analytic review. Personnel Psychology, 69(1), 67-121.

Maslyn, L. M., \& Uhl-Bien, M. (2001). Leader-member exchange and its dimensions: Effects of selfeffort and other's effort on relationship quality. Journal of Applied Psychology, 86, 679-708.

McCall, H., Arnold, V., \& Sutton, S. G. (2008). Use of knowledge management systems and the impact of the acquisition of explicit knowledge. Journal of Information Systems, 22(2), 77-102.

McIlveen, P., Beccaria, G., \& Burton, L. J. (2013). Beyond conscientiousness: Career optimism and satisfaction with academic major. Journal of Vocational Behavior, 83(3), 229-236.

McIntire, S. A., \& Miller, L. A. (2007). Foundations of psychological testing: A practical approach. Thousand Oaks, CA: Sage.

Nahrgang, J. D., Morgeson, F. P., \& Ilies, R. (2009). The development of leader-member exchanges: Exploring how personality and performance influence leader and member relationships over time. Organizational Behavior and Human Decision Processes, 108, 256-266.

Ng, T. W. H, \& Feldman, D. (2009). How broadly does education contribute to job performance. Personnel Psychology, 62(1), 89-134.

Nie, D., \& Lämsä, A. (2015). The leader-member exchange theory in the Chinese context and the ethical challenge of Guanxi. Journal of Business Ethics, 128, 851-861.

Niehoff, B. P. \& Moorman, R. H. (1993). Justice as a mediator between methods of monitoring and organizational citizenship behavior. Academy of Management Journal, 36(3), 527-556.

Novak, M. A., \& Graen, G. (1987). Perceived leader control as a moderator of personal leader resources contributing to leader-member exchange. Proceeding of the annual Academy of Management Conference, 206-209.

Nunnally, J. C., \& Berstein, I. H. (1994). Psychometric theory. New York, NY: McGraw-Hill.

Ordun, G., \& Acar, A. B. (2014). Impact of emotional intelligence on the establishment and development of high quality leader member exchange (LMX). Advances in Management \& Applied Economics, 4(2), 111-129.

Organ, D. W., Padsakoff, P. M., \& MacKenzie, S. B. (2006). Organizational citizenship behavior: Its nature, antecedents, and consequence. Thousand Oaks, CA: Sage.

Phillips, A. S., \& Bedeian, A. G. (1994). Leader-follower exchange quality: The role of personal and interpersonal attributes. Academy of Management Journal, 37(4), 990-1001.

Ployhart, R. E., Van Iddekinge, C. H., \& Mackenzie Jr, W. I. (2011). Acquiring and developing human capital in service contexts: The interconnectedness of human capital resources. Academy of Management Journal, 54(2), 353-368.

Ree, M.J., Earls, J.A., \& Teachout, M.S. (1994). Predicting job performance: Not much more than $g$. Journal of Applied Psychology, 79(6), 518-524.

Reed, K. K., Srinivasan, N., \& Doty, D. H. (2009). Adapting human and social capital to impact performance: Some empirical findings from the U.S. personal banking sector. Journal of Managerial Issues, 21(1), 36-57.

Scandura. T. A., Graen, G. B., \& Novak, M. A. (1986). When managers decide not to decide autocratically: An investigation of leader-member exchange and decision influence. Journal of Applied Psychology, 71(4), 579-584.

Scandura, T. A., \& Lankau, M. J. (1996). Developing diverse leaders: A leader-member exchange approach. Leadership Quarterly, 7, 243-263.

Schmidt, f. L., \& Hunter, J. (2004). General mental ability in the world of work: Occupational attainment and job performance. Journal of Personality and Social Psychology, 86, 162-173. 
Schriesheim, C. A., Castro, S. L., \& Cogliser, C. C. (1999). Leader-member exchange (LMX) research: A comprehensive review of theory, measurement, and data-analytic practices. Leadership Quarterly, 10(1), 63-113.

Schyns, B., Paul, T., Mohr, G., \& Blank, H. (2005). Comparing antecedents and consequences of leadermember exchange in a German working context to findings in the US. European Journal of Work and Organizational Psychology, 14(1), 1-22.

Sears, G. J., \& Hackett, R. D. (2011). The influence of role definition and affect in LMX: A process perspective on the personality-LMX relationship. Journal of Occupational and Organizational Psychology, 84, 544-564.

Settoon, R. P., Bennett, N., \& Linden, R. C. (1996). Social exchange in organizations: Perceived organizational support, leader-member exchange, and employee reciprocity. Journal of Applied Psychology, 81, 219-227.

Sheer, V. C. (2015). "Exchange lost" in leader-member theory and research: A critique and reconceptualization. Leadership, 11(22), 213-229.

Stark, E., \& Jeffries, F. L. (2011). Social capital via leader-member exchanges: An avenue to human capital? Current Topics in Management, 15, 117-136.

Stark, E., \& Poppler, P. (2009). Leadership, performance evaluations, and all the usual suspects. Personnel Review, 38(2), 320-328.

Srivastava, P., \& Hopwood, N. (2009). A practical iterative framework for qualitative data analysis. International Journal of Qualitative Methods, 8(1), 76-84.

Tabachnick, B. G., \& Fidell, L. S. (2013). Using multivariate statistics. New York, NY: Pearson.

Tidwell, N. D., Eastwick, P. W., \& Finkel, E. J. (2013). Perceived, not actual attraction in a live romantic context: Evidence from the speed-dating paradigm. Personal Relationships, 20(2), 199-215.

Tjosvold, D. (1989). Interdependence and power between managers and employees: A case study of the leader relationship. Journal of Management, 15, 49-62.

Uhl-Bien, M., \& Maslyn J. M. (2003). Reciprocity in manager-subordinate relationships: Components, configurations, and outcomes. Journal of Management, 29, 511-532.

Van Dyne, L., Cummings, L.L. \& McLean Parks, J. (1995). Extra-role behaviors: in pursuit of construct and definitional clarity (a bridge over muddied waters), in Cummings, L.L. and Staw, B.M. (Eds), Research in Organizational Behavior, 17, JAI Press, Greenwich, CT, 215-285.

Van Dyne, L. V., Graham, J. W., \& Dienesch, R. M. (1994). Organizational citizenship behavior: Construct redefinition, measures, and validation. Academy of Management Journal, 37(4), 765802.

Van Iddekinge, C. H., Aguinis, H., \& Mackey, J. D. (2017). A meta-analysis of the interactive, additive, and relative effects of cognitive ability and motivation on performance. Journal of Management, 44(1), 249-279.

Van Iddekinge, C. H., \& Ployhart, R. E. (2008). Developments in the criterion-related validation of selection procedures: A critical review and recommendations for practice. Personnel Psychology, 61(4), 871-925.

Wakabayashi, M., \& Graen, G. B. (1984). The Japanese career progress study: A 7-year follow-up. Journal of Applied Psychology, 69(4), 603-614.

Warrick, D. D. (2016). What leaders can learn about teamwork and developing high performance teams from organizational development practitioners. Performance Improvement, 55(3), 13-21.

Walumbwa, F. O., Cropanzano, R., \& Goldman, B. M. (2011). How leader-member exchange influences effective work behaviors: Social exchange and internal-external efficacy perspectives. Personnel Psychology, 64, 739-770.

Wang, H., Law, K. S., Hackett, R. D., Duanxu Wang, \& Zhen Xiong Chen (2005). Leader-member exchange as a mediator of the relationship between transformational leadership and followers' perception of organizational citizenship behaviors. Academy of Management Journal, 48(3), 420432. 
Wayne, S. J., Liden, R. C., \& Sparrowe (1994). Developing leader-member exchanges: The influence of gender and ingratiation. American Behavioral Scientist, 37(5), 694-714.

Wayne, S. J. Shore, L. M. and Liden, R. C. (1997). Perceived organizational support and Leader-Member Exchange: A social exchange perspective. Academy of Management Journal, 40(1), 82-111.

Williams, L. J., \& Anderson, S. E. (1991). Job satisfaction and organizational commitment as predictors of organization citizenship and in-role behaviors. Journal of Management, 17(3), 601-617.

Wilson, K. S., Sin, H-P, \& Conlon, D. E. (2010). What about the leader in leader-member exchange? The impact of resource exchanges and substitutability on the leader. Academy of Management Review, 35(3), 358-372.

Yu, A., Matta, F. K., \& Cronfield, B. (2018). Is leader-member exchange differentiation beneficial or detrimental for group effectiveness? A meta-analytic investigation and theoretical integration. Academy of Management Journal, 61(3), 1158-1188.

Yukl, G. (1998). Leadership in organizations ( $4^{\text {th }}$ ed.). Englewood Cliffs, NJ: Prentice-Hall. 